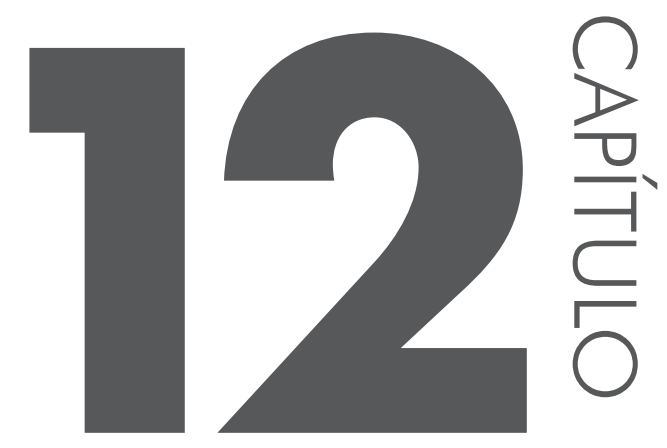

\title{
As narrativas orais ovimbundu como espaço de produção de sentidos
}

\section{Nsimba José}

Universidade Agostinho Neto

\author{
Ovindele visonehã alivulo, etu tusonehã vutima \\ Os brancos escrevem livros, nós escrevemos no peito
}

(Provérbio ovimbundu)

\section{Introdução}

O presente estudo visa analisar as narrativas orais ovimbundu vistas como espaço de interseção de saberes que revelam toda uma experiência sensível relativa aos aspectos de ordem material e imaterial. Decorrentes de uma criação estético-verbal fictícia, elas representam realidades diversas, evidenciando-se como respostas às interrogações dos homens, no seu dia a dia. Para a análise das referidas narrativas, propomos um modelo de leitura que se constrói a partir do diálogo que se estabelece entre as premissas teóricas de autores como Vladimir Propp, Claude Bremond e Paul Larivaille. A ideia é vermos a organização interna das narrativas e percebermos a maneira como as instâncias lógicas se articulam no seu interior, por um lado, e como, por outro, considerando os contextos de sua enunciação, proliferam significados. Quanto à estruturação do presente estudo, 
no começo, vamos apresentar um breve retrato sobre os ovimbundu, grupo étnico angolano detentor de um riquíssimo reportório histórico-cultural do qual adquirimos as narrativas a serem analisadas. A seguir, reservamos um espaço para nos debruçarmos acerca da tradição oral nos espaços socioculturais bantu, seguindo-se à interpretação das narrativas ovimbundu.

\section{Os ovimbundu: um breve retrato}

Antes de entrarmos no tema central da nossa pesquisa, vamos apresentar, de maneira sucinta, os ovimbundu, grupo etnolinguístico angolano donde as narrativas a serem abordadas têm origem. ${ }^{51}$ Os ovimbundu pertencem ao vasto tronco genealógico dos chamados povos bantu. Habitam o planalto central de Angola, que, em termos administrativos, abrange as seguintes províncias: Benguela, Bié e Huambo. No nordeste, a zona planáltica estende-se até a faixa sul da província de Malanje, ao passo que a sul vai até à metade da Húla. Estima-se que essa região é habitada por mais de 5.500.000 habitantes (MALUMBU, 2005). Na vertente da geografia econômica e dos recursos humanos, o planalto central apresenta uma configuração cujo panorama tem formas variadas. É abundante em riachos e rios de forte caudal, os quais permitem que tenha uma excedente produção agropecuária influenciada com os aluviões que se acumulam ao longo dos rios e das regiões baixas, o que, na verdade, tem favorecido a prática da agricultura, pesca e pastorícia (MALUMBU, 2005).

A sua fauna e flora são fascinantes e diversificadas: têm capim, plantas medicinais, savanas e variadíssimos animais que fazem parte não somente de sua economia de subsistência, mas também do seu imaginário, ou seja, integram a literatura expressa em umbundu, língua falada pelos ovimbundu, que, dentre outras variantes, tem as seguintes: mbalundu, ndombe, nganda, viye e wambu (FERNANDES; NTONDO, 2002).

A literatura oral ovimbundu está impregnada de vários gêneros orais, como os de maior extensão estrutural (contos, lendas, mitos) e os de menor extensão estrutural (adivinhas, adágios, canções, orações, provérbios) conservados na memória dos seus detentores: anciãos, chefes de famílias, homens, mulheres e crianças. ${ }^{52}$ É importante ressaltar que os povos da região planáltica, à semelhança de

51 Os textos a serem estudados são três. Foram recolhidos no município da Caala, província do Huambo, em setembro de 2014, quando da nossa pesquisa de campo, que consistiu em recolher seletivamente as narrativas orais em umbundu.

52 É importante referir que, de uma maneira geral, entre os povos africanos, há textos orais que são do domínio restrito, ou seja, tendo em conta a sua dimensão místico-esotérica ou mesmo histórica, não podem ser conhecidos pela sociedade, porque constituem o segredo dos clãs, 
todos os outros povos do mundo, têm uma memória prodigiosa. Há milhares de anos que conservam em sua memória milhares de adivinhas, adágios, canções, contos, invocações, lendas e mitos, listas de lugares, listas genealógicas e muito mais, os quais têm a palavra como seu principal vetor.

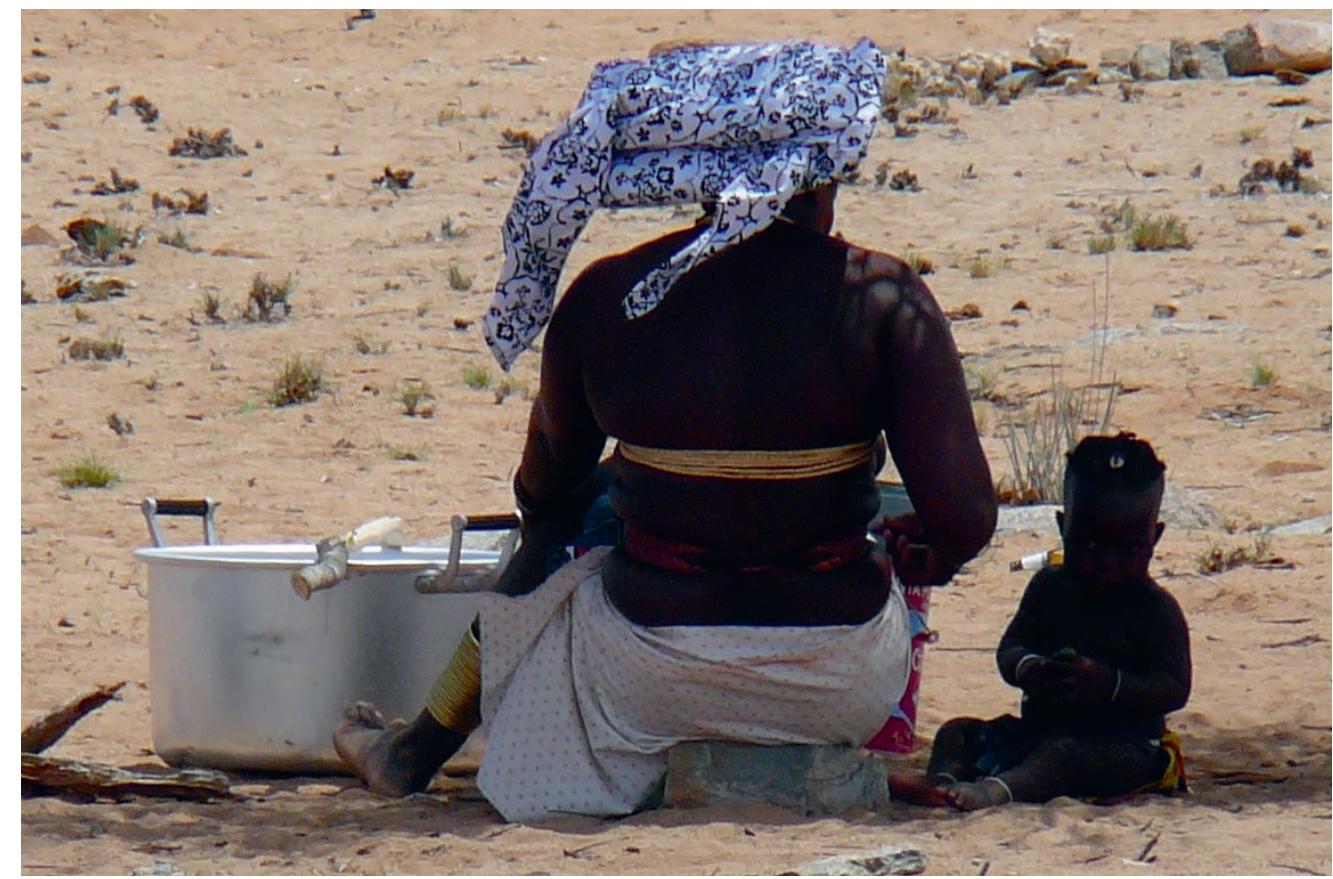

Figura 12.1 - Cozinha tradicional do Namibe. Fonte: foto de Ilka Boaventura Leite, 2012.

\section{Aspectos da tradição oral}

Quando falamos de narrativas orais, assim como de outros textos estéticos que se materializam com a palavra falada, estamos diante um tipo de comunicação que encontra as raízes históricas nas chamadas sociedades de tradição oral, opostas das sociedades de tradição escrita, conforme veremos a seguir.

Segundo Calvet (2011), esses dois tipos de sociedades, para o efeito de simplificação, podem ser reduzidas a quatro casos específicos: (i) as sociedades de tradição escrita antigas, nas quais língua escrita é utilizada na comunicação oral do dia a dia das pessoas; (ii) as sociedades de tradição escrita antigas, nas quais a língua escrita não é aquela que é utilizada na vida cotidiana dos seus locutores;

famílias e mesmo de profissionais como os das escolas iniciáticas, quer masculinas, quer femininas. 
(iii) as sociedades nas quais se introduziu recentemente a prática alfabética, onde foram impostas as línguas dos colonizadores; e (iv) as sociedades de tradição oral, onde a oralidade, contrariamente à escrituralidade, vista como codificação gráfico-visual do alfabeto verbal, representa uma comunicação que privilegia a percepção auditiva da mensagem impregnada de um significado conceitual e simbólico.

As sociedades africanas são sociedades de tradição oral, apesar de nelas ter sido introduzida a escrita alfabética decorrente do contato com os árabes e os europeus. Desse modo, pode se dizer que nas sociedades em questão é visível, seguindo o plano abstrato de Zumthor (2011), a oralidade primária e imediata, ou pura, sem contato com a escrita, assim como a oralidade coexistente com a escrita, que pode funcionar de dois modos diferentes: seja como oralidade mista, quando a influência da escrita aí contínua externa, parcial ou retardada, como acontece na África e na América; seja como oralidade segunda, que recompõe a partir da escrita e no interior de um meio em que predomina sobre os valores da voz na prática e no imaginário.

É interessante sublinhar a importância que os bantu dão à voz, à palavra falada, pois, praticamente, na vida, nada tem um fundamento sem ela. Como vimos atrás, para além de a língua possuir uma carga conceitual, nessas sociedades existem certas formas de comunicação oral que são separadas da fala comum. Nesse tipo de fala incomum, a voz humana representa um conjunto de valores que não são comparáveis a nenhum outro, valores fundadores de uma cultura, criadores de inumeráveis formas de arte (ZUMTHOR, 2005). Essas variadíssimas formas artísticas orais (adivinhas, anedotas, canções, contos, epopeias, lendas, mitos, orações, provérbios e outras) encontram as suas raízes nas sociedades antigas. Elas estabelecem uma relação dialógica com o momento em que são enunciadas, sem ignorar os aspectos extratextuais como entonações, danças, deslocações e gestos que as integram, completando, às vezes, o sentido daquilo que é proferido, narrado ou cantado. Não sendo nosso interesse estudar todos os textos de natureza oral, vamos prestar maior atenção às narrativas, ${ }^{53}$ mais precisamente contos e fábulas. ${ }^{54}$ Por narrativas orais, entendemos uma história de caráter figurativo que

53 Barthes (2013) foi claro em dizer que são inúmeras as narrativas do mundo. A narrativa pode ser sustentada pela linguagem articulada, oral ou escrita, pela imagem, fixa ou móvel, pelo gesto ou pela pintura ordenada de todas as substâncias, ou seja, está presente no mito, na lenda, na fábula, no conto, na novela e muito mais.

54 Concordamos com Goody (2010) quando diz que certos tipos de textos orais, como contos e fábulas, atravessam as fronteiras sociopolíticas e linguísticas de forma livre, sofrendo adaptações à medida que vão passando pelas bocas de contadores de histórias individuais. Isso acontece porque são considerados livres, ou seja, admitem a variação provocada pelo contador. Sua transformação é motivada por ele, sendo o mesmo também influenciado por fatores 
comporta valores culturais de uma determinada comunidade com raízes e personalidade regionais, muitas vezes perdidas na amálgama da modernidade (ROSÁRIO, 1989). Para esse autor moçambicano, na sociedade africana, em particular a campesina, em que a tradição oral é o veículo fundamental de todos os valores - quer educacionais, quer sociais, quer político-religiosos, quer econômicos, quer culturais - apercebe-se mais facilmente que as narrativas são a mais importante engrenagem na transmissão desses valores. Do ponto de vista da sua forma, são geralmente em prosa e registram um número reduzido de personagens. Ao contrário do conto, que tem como personagens seres humanos, a fábula, de caráter doutrinário e alegórico, encena animais, plantas, seres inanimados. Essas narrativas, ao encenarem as personagens numa determinada situação de instabilidade ou de instabilidade, reservam o triunfo e a felicidade ao herói, que varia de região a região.

Vale sublinhar que, de uma maneira geral, em todas as culturas, esse sujeito da narrativa é sempre o vencedor, não importando a grandeza, a força, a astúcia etc. de que o seu adversário é portador, porque, por mais apático que ele pareça, por mais desvantagens que tenha no decurso da história, ele tem sempre a possibilidade de vencer. Caso não pela inteligência ou perspicácia que lhe é facultada pela comunidade, é pela ajuda de um auxiliar, às vezes mágico (JOSÉ, 2010). Tendo em conta esse aspecto, supõe-se que o que está na base da inviolabilidade dos seus papéis e status nas narrativas seja o direito ao mérito que lhe é conferido pela comunidade em forma de direito natural inalienável, tradicionalmente consagrado nos princípios que regem a vida da comunidade (JOSÉ, 2010).

A enunciação dos textos orais poéticos entre os africanos é dependente de contextos, os quais determinam a escolha do gênero textual, da parte do intérprete, em função a fatores como idade do ouvinte. ${ }^{55}$ Entre os ovimbundu e os demais povos do grupo bantu, os textos orais a que estamos a nos referir neste trabalho têm como espaço de maior difusão as aldeias, o que não significa que a sua proliferação não ocorra nos centros urbanos. Na verdade, são várias as situações da sua enunciação, mas citaremos algumas para justificarmos o que estamos a comentar. Por exemplo, havendo desentendimento entre duas ou mais pessoas, alguém, no meio envolvente, pode proferir um provérbio cuja finalidade é redimir o conflito.Nessa vertente, estamos diante de uma produção poética oral com uma dimensão utilitária e finalística, uma vez que serve de resposta aos vários proble-

que podem ser de ordem sociológica, psicológica ou outras, fazendo com que os textos dessa natureza ampliem, reduzam ou assimilem elementos decorrentes da atualidade nos domínios sociais, políticos, militares, ideológicos, econômicos e tecnológicos.

55 É preciso explicar que há textos orais enunciados e ouvidos singularmente pelo seu executante. É o caso de canções cantadas por um intérprete quando caminha sozinho. 
mas do cotidiano. Um outro exemplo: entre os ovimbundu, há canções cantadas por mulheres quando moem o milho nas pedras para produzirem a sua farinha. Sentadas no chão, enquanto moem o milho, cantam em conjunto, tematizando, entre os assuntos, o amor ao trabalho, (re)introduzindo a mulher em atividades produtivas.

Segundo Malumbu (2005), para os ovimbundu, não existe melhor método de introduzir as pessoas em novos conhecimentos e de as forjar nos usos, nos costumes, nas tradições e nas crenças senão através da participação direta nas manifestações sociais dessas atividades. Entre eles, diz o citado autor, no processo de educação não formal, está o ondjango, escola tradicional reconhecida dentro da estrutura da família alargada aonde as crianças são conduzidas para aprenderem, com os mais velhos, aspectos da vida no sentido geral, que exerce um papel importante na educação, justamente porque reúne os mestres de cerimônia para transmitirem os seus conhecimentos acumulados ao longo dos tempos aos mais novos. No ondjango, as narrativas orais, assim como os outros textos materializados com o código oral, como o provérbio e a advinha, são também tidos como objeto de ensino-aprendizagem.

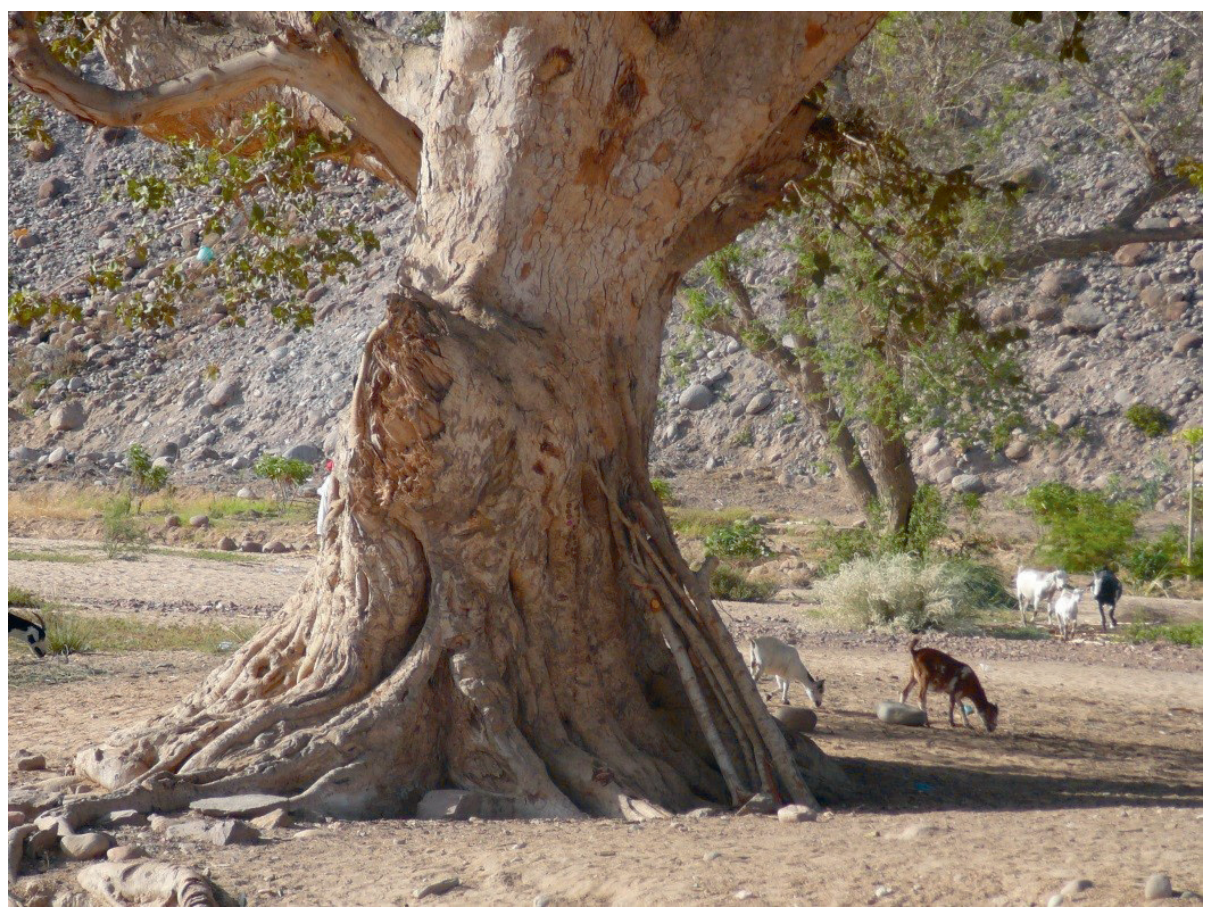

Figura 12.2 - Figueira do deserto. Fonte: foto de llka Boaventura Leite, 2012. 


\section{Aspectos teóricos e metodológicos}

Os estudos cujos enfoques recaem para a narrativa são inúmeros. Todavia, tendo em atenção os objetivos que pretendemos atingir, vamos revisitar as teorias de Vladimir Propp, Claude Bremond e Paul Larivaille, no sentido de, a partir deles, fundamentarmos o modelo de leitura que adotamos, a fim de analisarmos os textos selecionados para o nosso estudo.

Em Morfologia do conto maravilhoso, Propp (2006), analisando um corpus de cem contos russos, descobriu que havia neles elementos constantes e variáveis. Para ele, o que muda são os nomes (e, com eles, os atributos) das personagens, e o que não muda são suas ações, ou funções (num total de trinta e uma funções). Propp descobriu também que a sequência das funções era sempre idêntica, mas chama atenção para o fato de que essa premissa tem a ver somente com o folclore e não com os contos criados artificialmente. Uma outra questão que merece destaque no trabalho desse teórico russo é o momento estático caracterizado pela situação inicial e situação final como ponto de partida e ponto de chegada da narrativa, que pode ser eufórico ou disfórico.

Em síntese, o que ele procurou fazer foi estudar formas e o estabelecimento das leis que regem a disposição dos contos maravilhosos russos. Para o efeito, foi possível analisá-los através do processo de segmentação, que consistiu em enumerar as funções. A cada uma delas atribuiu uma breve descrição da sua essência, definição reduzida numa palavra e o seu signo convencional.

Essas e outras conclusões esboçadas por Propp despertaram o interesse de vários pesquisadores, como Levi-strauss, Roland Barthes, A. J. Greimas, Claude Bremond, Tzevetan Todorov e Cesare Segre. Bremond (2013), por exemplo, ao revisar o trabalho de Propp, centra-se na própria lógica da narrativa, propondo um modelo de análise extensivo para os enunciados narrativos, pois não se limita aos contos da tradição oral, como Propp. O modelo do teórico francês é baseado em quatro regras que passamos a enumerar: (i) o átomo narrativo é a função, conforme Propp; (ii) $\mathrm{O}$ agrupamento de três funções engendra a sequência elementar, a qual corresponde às três fases obrigatórias de todo processo, sendo que a primeira abre a possibilidade do processo, a segunda, o processo de atualização de uma possibilidade, e a terceira, uma ação que fecha o processo sob a forma de resultado esperado; (iii) tratando-se de possibilidades, as sequências não são preestabelecidas, e as funções nelas relacionam-se em forma de árvore, encaixando função de objetivo, de atualização e de fim (a primeira função apresenta o objetivo do herói, abrindo as possibilidades de ação, a segunda seleciona uma das possíveis ações do herói para atualizá-la, e a terceira conclui o sucesso ou a falha do herói em atingir seu objetivo); (iv) as sequências elementares combinam-se entre si para engendrar as sequências complexas. A crítica de Bremond a Propp as- 
senta, entre outros aspectos, no fato de a metodologia daquele ter se limitado ao conto maravilhoso e desconsiderar a intervenção do narrador, porque dirigia todo o seu trabalho apenas para uma codificação finalista das funções, que também foram alvo de críticas e revisões (ROSÁRIO, 1989; SEGRE, 1999; BREMOND, 2013; GREIMAS, 2013).

Portanto, sem minimizar as propostas de Propp e Bremond, segundo Rosário (1989), Paul Lavivaille, que se situa na linha desses teóricos, tenta revisar o esquema canônico de Propp e suas trinta e uma funções. Ao teorizar sobre o enredo da narrativa, Paul Larivaille propõe um esquema pentadimensional, o qual divide o enredo em cinco partes.

Ele considera os momentos estáticos descobertos por Propp: situação inicial e situação final (eufórico ou disfórico), conforme assinalado atrás. Entre esses dois momentos, aponta três: perturbação, transformação e resolução, considerados momentos dinâmicos. A perturbação resulta da introdução de um elemento que desequilibra a estabilidade, ao passo que a transformação, fase subsequente, representa a unidade onde se efetuam os diversos passos que levam ao realinhamento que permite um desenlace. Ao contrário disso, a resolução é uma espécie de recomposição de desordem provocada pelo primeiro momento dinâmico.

Feita essa síntese teórica, podemos dizer que são vários os ângulos de incidência dos autores com quem estamos a trabalhar, porém, considerando as questões de ordem metodológica, vamos privilegiar somente os aspectos que se enquadram no nosso trabalho. Desse modo, parece-nos viável aplicar o modelo de análise pentadimensional, pois, considerando o seu carácter operativo, permite-nos decompor e recompor a sintaxe das narrativas e verificar a sucessão dos seus segmentos correlacionados suscetíveis de receber uma explicação contextualizada, que mostra como se produz e se interpreta o sentido das mesmas. É assim que vamos proceder nas páginas subsequentes, ou seja, vamos apresentar as narrativas ovimbundu uma por cada vez, seguindo-se depois a sua análise. 


\section{O jovem à procura de uma mulher}

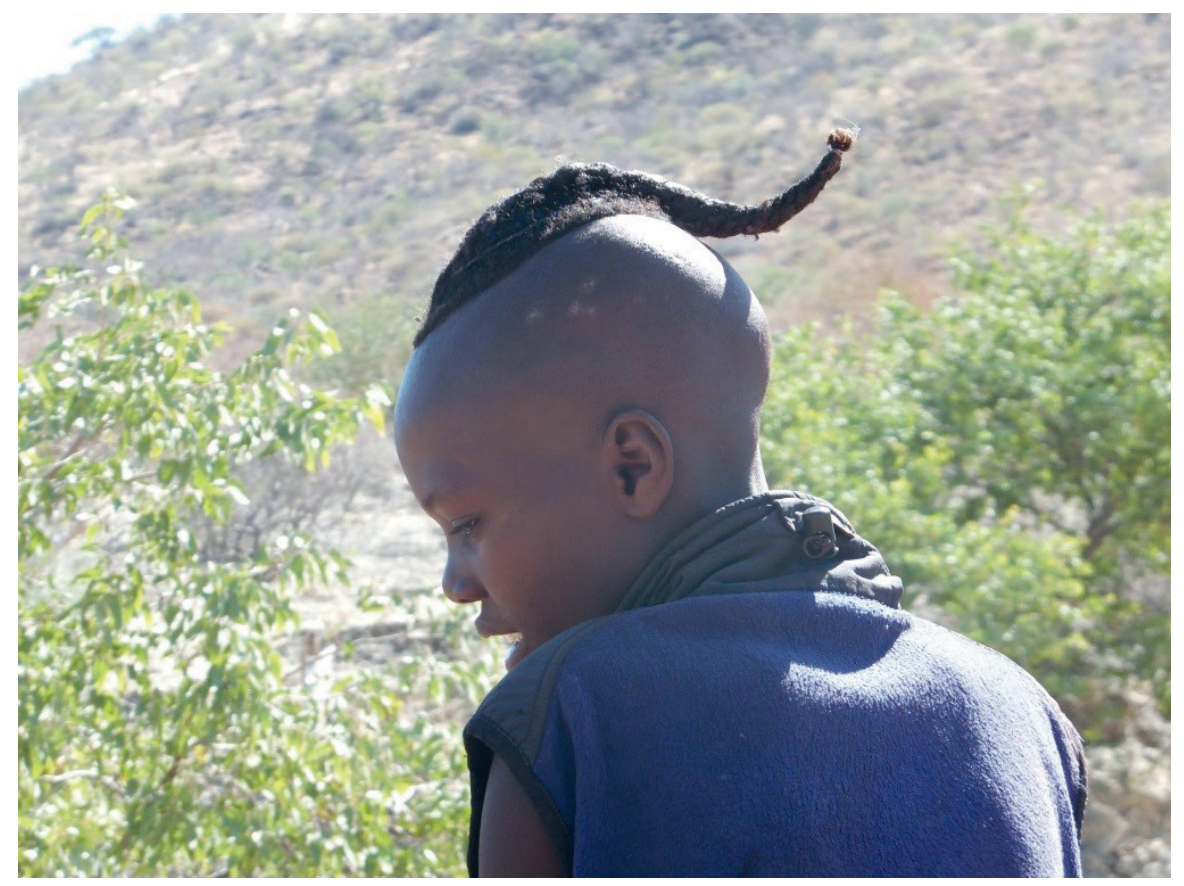

Figura 12.3 - Jovem pastor do Namibe. Fonte: foto de Nazareno Campos, 2014.

Era uma vez, um moço saiu da sua aldeia à procura de uma moça. Quando chegou à outra aldeia, disse aos seus amigos que ele estava à procura de uma moça que fosse muito bonita para casar-se com ela.

- Amigos, quero uma daquelas que todo o mundo considera a mais linda desta aldeia - disse o jovem.

E um deles respondeu:

- Nesta aldeia, há uma moça muito bonita, mas não será possível, porque não conseguirás dar aquilo que os pais dela te vão pedir.

- Eu vou tentar. Quero saber o que os pais dela vão pedir.

Chegado à casa dos pais da moça, eles perguntaram:

- O que é que o senhor quer?

- Quero pedir a vossa filha em casamento. Respondeu o jovem.

- Está bem. Nós não exigimos muito para o casamento. Traz apenas um saco de ar.

- Não há problemas. Por enquanto eu gostaria de pedir aos pais uma rodilha de fumo para por à cabeça durante a transportação de ar. 
Com a resposta do rapaz, os pais descobriram tratar-se de um rapaz esperto, que tinha muito juizo, e disseram:

- Você é filho dum soba. Pode levar a nossa filha em casamento. Nós também não temos lugar nenhum onde podemos buscar uma rodilha de fumo.

A narrativa apresentada, como se pode observar, começa com uma situação inicial instável, ou seja, nela, subjaz a ideia de carência, pois há um jovem que procura por uma mulher para casar. Quando ele manifesta o interesse aos seus amigos em querer ter a moça mais linda da aldeia, em resposta, um dos amigos diz que é difícil, porque os pais dela pedem algo em casamento da filha que nunca um homem conseguiu dar. Isso representa a perturbação, expressão de contrariedade, contraposta ao desejo do jovem que vai conversar com os pais da moça.

Quer isso dizer que o texto sugere termos disjuntivos: entenda-se negação/ aceitação. Percebe-se que, se por um lado os amigos mostram-se céticos ao desejo do jovem, este contraria-os e vai conversar com os pais da moça com quem deseja casar. Dito de outra maneira, a perturbação representa uma obstrução, mas é ultrapassada, pois o desafio surge como a possibilidade de se ultrapassar a situação crítica ou conflituante. Relativamente a essa questão, como é sabido, "nas estórias de qualquer tipo e gênero, é o conflito - seja ele de que tipo for e tenha a dimensão que tiver (interpessoal, psicológico, religioso, político, ideológico etc.) que estimula a catarse e os processos cognitivos” (MOTTA, 2013, p. 167).

Aliando esse aspecto com o comentário, podemos dizer que a introdução do elemento perturbador abre espaço para novas ações e sequências que se estendem até ao fim da narrativa. O exemplo disso é o fato de depois da transformação seguir-se um outro segmento narrativo, a resolução, na qual, seguindo os traços presentes no texto, tem um sinal positivo, na medida em que, quando o jovem chega aos pais da moça, é-lhe pedido um "saco de ar" como requisito para o matrimônio. De seguida, replicando, ele pede aos pais da moça uma "rodilha de fumo" para transportar o "saco de ar" na cabeça. Depois de os pais ouvirem a resposta sábia do jovem, deram-lhe a filha.

\section{O macaco e o cágado}

Era uma vez, havia um macaco que estava doente há muito tempo. Tomava remédios, mas a sua saúde não melhorava.

Certo dia, resolveu ir a um curandeiro. Quando chegou à casa deste, explicou tudo o que sentia.

O curandeiro ouviu-o atentamente e disse-lhe:-Para te curares, é necessário que comas coração de um macaco. 
Este aceitou cumprir as orientações do curandeiro. Porém, ao invés de procurar pelo coração do animal que lhe tinha sido recomendado, foi a um rio onde estava o cágado sentado sobre uma pedra e disse-lhe:

- Tio, preciso da sua ajuda.

- Em que lhe posso servir? Perguntou o cágado ao macaco.

- Fui a um quimbanda para ser tratado. Ele orientou-me para comer o coração de cágado. O tio pode me dar o seu?

Em resposta, o cágado disse:

- Dar-te-ei o coração que deixei na outra margem do rio.

O macaco pediu ao cágado que subisse nas suas costas para que atravessassem o rio depressa. O cágado subiu e foram. Quando chegaram lá, ele descen e foi algures em busca do suposto coração. Mas como a demora era tanta, o macaco que estava à espera há muito tempo, clamou:

- Tio, onde está? E por que demora?

- Meu sobrinho, já algum dia viu um animal a tirar o seu coração? Eu nunca the darei o meu. Respondeu o cágado.

Quando o macaco ouviu estas palavras, ficou desmoralizado. Regresson muito triste à aldeia onde morreu.

À semelhança do primeiro texto analisado, esse também apresenta uma situação inicial instável. Retrata o estado precário da saúde do macaco que, apesar de tomar remédio durante algum tempo, não melhorava. A sua ida ao curandeiro denota a possibilidade de ultrapassar a situação crítica em que se encontra. Significa que se põe em causa dois saberes numa relação de invalidade e validade. Justifica-se, porque quando o macaco toma remédios implica que tem conhecimento medicinal, mas este falha, e é por isso que vai ao curandeiro a fim de ser tratado. Quando o curandeiro orienta o seu paciente que vá comer coração de um macaco e este aceita e vai à procura do objeto, ocorre uma manipulação. $\mathrm{O}$ paciente é levado a agir segundo o querer do curandeiro.

Vendo bem, a perturbação é implícita, sendo que depois da situação inicial segue-se a transformação. Quer isso dizer que o texto em análise não apresenta uma rigidez estrutural. Essa questão remete-nos para um outro tipo de transformação: a transformação de natureza sintagmática que se refere à relação existente entre o universo da narrativa e o universo da sociedade que a produz (ROSÁRIO, 1989). Normalmente, conforme dito anteriormente, ocorre nos textos orais li- 
vres, os que admitem a variação em relação ao texto-modelo, ${ }^{56}$ que dá origem às diferentes versões. Isso acontece porque o intérprete tem a liberdade de criar e recriar uma série de combinações, reajustes dos episódios e outras alterações possíveis no texto. Contextualizando, nessa narrativa constata-se uma transformação do tipo redução. Apresenta um ligeiro desvio em relação ao modelo canônico, através da omissão ou supressão de um ou vários elementos do texto, quer por opção quer por esquecimento de quem o narra.Depois dessa breve incursão à volta das transformações das narrativas, resta-nos refletir sobre a resolução e a situação final. De acordo com o texto em análise, quando o curandeiro orienta o macaco para comer o coração do animal da mesma espécie, este aceitou, mas simula, ou seja, ao invés de procurar pelo coração do animal que lhe tinha sido recomendado, foi a um rio onde estava o cágado e pediu que este lhe desse o seu coração. O cágado, simulando, aceitou, e assim o macaco ficou com a esperança de recuperar da doença que tinha. Portanto, nessa parte da narrativa, verificam-se, do ponto de vista dos discursos das duas personagens, as suas intenções e os efeitos esperados das mesmas pelas personagens e pelos ouvintes ou leitores. Nesse sentido, "taticamente, a estratégia narrativa cria expectativas, confronta rupturas com a expectativa pela normalização das coisas” (MOTTA, 2013, p. 156). É isso o que acontece. Enquanto o macaco espera pelo cágado para lhe dar o seu coração, quer dizer que espera do outro o resultado positivo da artimanha por si planejada.

No entanto, o cágado, como força oposta, também socorre-se da mesma estratégia a seu favor, o que revela uma dicotomia: vida/morte, justificando os interesses das duas personagens. Acontece que o cágado vence e o macaco perde. Este fato mostra, nas relações sociais, isso é, no contexto da narrativa em análise, a punição da ingenuidade do macaco, enquanto o cágado não possui um sinal negativo, etnologicamente e simbolicamente.

\section{O caçador e o elefante}

Era uma vez, um caçador resolveu ir à caça. Pelo caminho, encontrou um elefante morto e decidiu regressar à casa para que fosse buscá-lo no dia seguinte. Quando chegou, contou à sua mulher o que tinha visto, advertindo-a que não contasse a ninguém porque, se o segredo fosse revelado, a carne do elefante seria partilhada na aldeia.

56 Conforme dito anteriormente, as narrativas orais que têm vindo a circular há milhares de anos nas diversas partes do mundo, de geração a geração, por sofrerem permanentes reciclagens ou reajustes, chegam-nos sempre como fragmentos, difíceis de serem reconstruídas para se obter o texto-modelo, dito de outra maneira, a narrativa derivante. 
Na manhã do dia seguinte, saiu para ir buscar o elefante. Porém, pelo caminho, viu um passarinho que atraiu a sua atenção e resolveu segui-lo. Cada vez que o seguia, o passarinho fugia e cantava:

- Não te preocupes comigo. Vai buscar o que você deixou, porque senão vais perder tudo.

O caçador seguia o passarinho, e este fugia cada vez mais e cantava:

- Não te preocupes comigo. Vai buscar o que você deixou, porque senão vais perdê-lo.

O caçador seguiu o passarinho o dia todo e não o apanhou até que ficou tarde, e resolveu ir onde tinha encontrado o elefante para levá-lo à sua casa.

Quando chegou no local onde tinha visto o elefante, não encontrou nada, porque, afinal, enquanto ele seguia o passarinho, os outros caçadores que iam à caça viram o grande animal pelo caminho e levaram-no à casa do soba. Pois, como dizem as regras da comunidade, caso alguém encontrasse um animal morto pelo caminho, tinha de transportá-lo à aldeia a fim de ser dividido e comido por todos.

Quando o caçador chegou à aldeia, encontrou uma grande festa. Perguntou à sua esposa a que se devia a mesma, e esta contou tudo ao seu marido, que ficou muito triste e não aceitou participar da festa.

Já tivemos a oportunidade de analisar as narrativas anteriores e explicamos a maneira como se organizam e geram significados. Para terminarmos, importa proceder à análise deste último texto. A começar pela situação inicial, é visível a representação do caçador que vai à caça; é um indício da falta de algo que constitui um motivo determinante de incentivo para luta pela sobrevivência.

Pelo que se constata, depois da situação inicial, não é explícita a perturbação. Na transformação, a atualização temática é caracterizada pelo desejo do caçador que vai buscar o elefante onde o tinha encontrado. Porém, pelo caminho, vê um passarinho que atrai a sua atenção e resolve segui-lo, mas é advertido pelo passarinho, que fugia e cantava. Trata-se uma narrativa que se constrói na base de uma dualidade discursiva, que é uma das características das narrativas africanas no geral, e bantu, em particular, que dialogam com outros gêneros orais, como é o caso de canções.

Continuando, e tendo em atenção o segmento em análise, justifica a falta de descrições pormenorizadas nos textos dessa natureza na medida em que o passarinho surge de forma esporádica e, pelo que nos parece, reveste-se de valores a si atribuídos pelo imaginário grupal que os testa com os do seu opositor - o caçador. Aqui, subjaz a perseguição, fuga e alerta, como um processo em transcurso 
porque não se revela como uma situação estática e isolada na narrativa, pelo contrário, é parte dela. Basta observar que evolui e estabelece relações dialógicas com as outras instâncias narrativas, mais precisamente com a situação final e não com a resolução que, como a perturbação, é implícita.

Quanto à situação final, é disfórica para o caçador. Conforme nos mostra o texto, ele perdeu muito tempo seguindo o passarinho e, quando o dia escureceu, resolveu ir buscar o elefante que tinha visto pelo caminho, mas não o encontrou, $\mathrm{e}$ isso deixou-o mais triste quando chegou à aldeia e apercebeu-se que a presa tinha sido transportada para a lá, e com ela fez-se a festa de que se recusou a participar. No contexto na narrativa em análise, é evidente a ideia da coesão comunitária. Entendemos que o indivíduo e o grupo mostram-se conciliados, ou seja, o indivíduo é consubstancial ao grupo. O contrário revela-se como ruptura aos princípios aceites pela comunidade, por isso é punido. E é o que acontece. O caçador, por valorizar a sua ambição desmedida, perdeu tudo.

\section{Considerações finais}

Feito este estudo, revela-se importante considerar os seguintes aspectos: as narrativas ovimbundu aqui analisadas, do ponto de vista da sua organização interna, não apresentam uma rigidez estrutural, conforme tivemos a ocasião de explicar. Essas narrativas, no processo de encadeamento dos seus segmentos no nível profundo, propõem discursos cuja articulação privilegia termos opostos como aceitação versus negação, euforia versus disforia, para revelarem comportamentos e atitudes incorporados nas personagens que contracenam nelas.

Fora do universo textual, essas narrativas da tradição oral expressam a realidade humana simbolicamente representada para justificar situações de superfície social, constituindo-se, desse modo, respostas aos problemas do dia a dia dos seus produtores.

\section{Referências}

ALTUNA, P. R. R. A. Cultura tradicional Bantu. Luanda: Paulinas, 2006.

BÁ, H. A. A tradição viva. In: KIZERBO, J. K. (Org.). História geral da África I, metodologia e pré-história. São Paulo: Ática, 1982. p. 167-212.

BARTHES, R. et al. Introdução à análise estrutural da narrativa. 8. ed. Rio de Janeiro: Vozes, 2013.

BASCOM, W. The forms of folklore - prose narratives. The journal of the american folklore, v. 78, n. 307, p. 3-20, 1965. 
BREMOND, C. A lógica dos possíveis narrativos. In: BARTHES, Roland et al. Análise estrutural da narrativa: pesquisas semiológicas. Petrópolis: Vozes, 1973. p. 105-135.

CASCUDO, L. C. Literatura oral no Brasil. 3. ed. São Paulo: USP, 1984.

CALVET, L-J. Tradição oral \& tradição escrita. São Paulo: Parábola, 2011.

FERNANDES, J.; NTONDO, Z. Angola: povos e linguas. Luanda: Nzila, 2002.

FINNEGAN, R. Oral literature in Africa. United Kingdom: Open Book Publishers, 2012.

FONSECA, A. Contribuição ao estudo da literatura oral angolana. Luanda: Inald, 1996.

GOODY, J. O mito, o ritual e o oral. Rio de Janeiro: Vozes, 2012.

JOSÉ, N. A resolução de conflitos na narrativa oral Ovimbundu: o caso de contos na obra Os mais velhos disseram. 2010. 67 f. Monografia (Licenciatura em Línguas e Literaturas Africanas) - Instituto Superior de Ciências da Educação, Universidade Agostinho Neto, Luanda, 2010.

MELETÍNSKI, E. M. Mito e conto maravilhoso. In: BERNARDIDI, A. F.; NEKLIÚDOV, S. I. (Org.). A estrutura do conto de magia: ensaios sobre mito e conto de magia. Florianópolis: UFSC, 2015. p. 287-300.

MOISÉS, M. Os Ovimbundu de Angola: Tradição, Economia e Cultura Organizativa. Roma: Vivere In, 2005.

MOTTA, L. G. Análise crítica da narrativa. Brasília, DF: UnB, 2013.

NÓVIK, E. S. O sistema dos personagens do conto de magia russo. In: BERNARDINI, A. F.; NEKLIÚDOV, S. I. A estrutura do conto de magia: ensaios sobre mito e conto de magia. Florianópolis: UFSC, 2015. p. 149-194.

NUNES, S. D. M. A milenar arte da oratura angolana e moçambicana: aspectos estruturais e receptividade dos alunos portugueses ao conto africano. Edições Electrónicas, CEAUP, 2009.

PROPP, V. Morfologia do conto maravilhoso. 2. ed. Rio de Janeiro: Forense Universitária, 2006. 2002. . As raízes históricas do conto maravilhoso. 2. ed. São Paulo: Martins Fontes, ROSÁRIO, L. J. C. A narrativa africana de expressão oral. Lisboa: Instituto de Cultura e Língua Portuguesa, 1989.

SEGRE, C. Introdução à análise do texto literário. Lisboa: Estampa, 1999. 
WEITZEL, A. H. Folclore linguístico e literário. 3. ed. Juiz de Fora: UFJF, 2014.

ZUMTHOR, P. Performance, recepção e leitura. São Paulo: Cosac Naify, 2014.

. Introdução à poesia oral. Belo Horizonte: UFMG, 2010.

. Escritura e nomadismo. São Paulo: Estampa, 2005. 